\title{
Liberalismo y republicanismo en las sentencias de la Corte Interamericana de Derechos Humanos y los órganos jurisdiccionales de Chile: el caso de "La última tentación de Cristo"*
}

\author{
Liberal and Republican perspectives in the sentences of the \\ Inter-American Court of Human Rights and the jurisdictional \\ bodies of Chile: the case of "The Last Temptation of Christ"
}

Recibido: 04/03/18 Aprobado: 25/05/18

DOI: $h$ ttp://dx.doi.org/10.25054/16576799.1559

\section{RESUMEN}

Este artículo analiza y compara la sentencia de la Corte Interamericana de Derechos Humanos (CIDH) con la sentencia emitida por el Tribunal de Apelaciones de Santiago (TAS) en relación con la película la última tentación de Cristo de Martin Scorsese (1988). La hipótesis puesta a prueba es que la CIDH en su sentencia sobre el caso de la película "La última tentación de Cristo" hizo una interpretación liberal-constitucional, mientras que el Tribunal de Apelaciones de Santiago y la Corte Suprema de Justicia de Chile abordaron el problema desde una perspectiva cercana al republicanismo político. Este caso permite apreciar con nitidez cómo distintas concepciones de la teoría política se materializan concretamente y generan distintas consecuencias en las resoluciones de los órganos jurisdiccionales sobre los problemas políticos y sociales.

\section{PALABRAS CLAVE}

Chile; Corte Interamericana de Derechos Humanos; Liberalismo; Republicanismo; Tribunal de Apelaciones de Santiago.

\section{ABSTRACT}

This article analyzes and compares the judgment of the Inter-American Court of Human Rights (IACHR) and that of the Court of Appeals of Santiago (TAS by its Spanish acronym) in relation to the film The Last Temptation of Christ by Martin Scorsese (1988). The main hypothesis is that IACHR in its mandate made a liberal-constitutional interpretation of the issue, while the Court of Appeals of Santiago and the Supreme Court of Justice of Chile addressed the issue according to political republicanist perspective. This case allows us to clearly appreciate how different theoretical conceptions materialize concretely and generate different consequences in the decisions of jurisdictional bodies regarding political and social problems.

\section{KEYWORDS}

Chile; Court ofAppeals of Santiago; Inter-American Court of Human Rights; Liberal; Republican.

* Artículo de Investigación. "Investigación Apoyada por CONACYT". 


\section{INTRODUCCIÓN}

Este artículo analiza y compara la sentencia de la Corte Interamericana de Derechos Humanos (CIDH) con las sentencias emitidas por los órganos jurisdiccionales del Estado chileno en relación con la película "La última tentación de Cristo" de Martin Scorsese.

El argumento está centrado en la sentencia de la CIDH, la cual hace referencia al derecho a la libertad de pensamiento y expresión y, al derecho a la libertad de conciencia y de religión, en contraste con los argumentos de la sentencia del Tribunal de Apelaciones de Santiago (TAS), los cuales fueron ratificados por la Corte Suprema de Justicia de Chile (CSJCh).

La hipótesis a evaluar es que la CIDH en su sentencia sobre el caso de la película "La última tentación de Cristo" hizo una interpretación liberal-constitucional -articulación de la teoría liberal política-, mientras que el Tribunal de Apelaciones de Santiago y la Corte Suprema de Justicia de Chile abordaron el problema desde una perspectiva cercana al republicanismo político ${ }^{1}$. Este caso permite apreciar con nitidez cómo distintas concepciones teóricas se materializan concretamente y generan distintas consecuencias en las resoluciones sobre problemas políticos y sociales.

Para la realización de lo anterior, el documento está organizado de la siguiente manera: 1 . Se expone lo ocurrido con la película "La última tentación de Cristo" en los tribunales chilenos y en la $\mathrm{CIDH}$; 2 . Se discuten los planteamientos constitucional y republicano en relación a dos cuestiones: a) derechos y autonomía personal vs. virtuosismo cívico y autogobierno, y b) el papel del Estado; a la par de anterior, se intercalan y analizan las decisiones de las instancias jurisdiccionales; 3 . Se exponen algunas consideraciones finales.

\section{LA ÚLTIMA TENTACIÓN DE CRISTO Y SU PROHIBICIÓN: SENTENCIAS CONTRAPUESTAS}

La película "La última tentación de Cristo" fue censurada en Chile el 29 de noviembre de 1988 cuando el Consejo de Calificación Cinematográfica (CCC) rechazó su exhibición. Dicha decisión fue ratificada en marzo del año siguiente por un Tribunal de Apelación debido a que la empresa 'United International Pictures Ltda' apeló la decisión del Consejo. Posteriormente, en 1996, el CCC volvió a revisar la prohibición de la película ante una petición particular y autorizó su exhibición para espectadores mayores de 18 años de edad.

Ante ello, el 20 de enero de 1997, un grupo de ciudadanos interpuso un recurso de protección a nombre de ellos mismos, de Jesucristo y de la Iglesia Católica en el Tribunal de Apelaciones de Santiago, el cual decidió dejar sin efecto la resolución administrativa dictada por el CCC, restableciendo con ello la prohibición de la exhibición de la película con el argumento de que violentaba el derecho al honor de Jesucristo y sus creyentes (TAS, 1997, inciso $10)^{2}$. Ciudadanos inconformes con esa decisión, acudieron a la Corte Suprema de Justicia de Chile (CSJCh) para reclamar la sentencia; sin embargo, la Corte ratificó lo dicho previamente por el Tribunal de Apelación.

Es bajo este escenario que, el 3 de septiembre de 1997, la Comisión Interamericana de Derechos Humanos recibió una denuncia de la Asociación de Abogados por las Libertades Públicas A.G., quienes representando a la sociedad chilena y en contra del Estado, demandaban violaciones a sus derechos por la censura judicial impuesta a la exhibición del filme "La última tentación de Cristo" (CIDH, 2001, p. 2). Ante ello, el 15 de enero de ese año, la Comisión sometió ante la CIDH una demanda para que decidiera si el Estado había violado el artículo 13 sobre el derecho a la libertad de pensamiento y expresión y, el artículo 12 relacionado con la libertad de conciencia y religión; ambos de la Convención Americana de Derechos Humanos. La decisión de la CIDH fue unánime y opuesta a la sentencia emitida por la justicia chilena, pues señaló que el Estado chileno había violado el derecho a la libertad de pensamiento y de expresión de la Convención Americana, pero no el de libertad de conciencia y religión al prohibir la exhibición del filme. Asimismo, sentenció que Chile debía modificar su ordenamiento jurídico interno con el fin de suprimir o cambiar el artículo que establecía un sistema de censura para la exhibición y publicidad de la producción cinematográfica.

En suma, por lo planteado aquí, se sostiene que subsisten dos visiones contrapuestas acerca de un mismo fenóme-

1 - Si bien a lo largo del texto se hará referencia al liberalismo en su versión política, también se tomará en cuenta la dimensión moral, no considerándose la perspectiva económica de esta tradición. Asimismo, se utilizará -en pocas ocasiones-de manera indistinta el término constitucionalismo y liberalismo, debido a que el primero es heredero del segundo.

2 - 10) Que los recurrentes señalan a tal resolución como causa del agravio a la garantía indicada en el № 4 del artículo 19 de la Constitución que reza como sigue: "el respeto y protección a la vida privada y pública y a la honra de la persona y su familia", agravio que se habría producido, según aquellos lo sostienen en el recurso, a ellos mismos, a la persona de Jesucristo y a la persona jurídica Iglesia Católica. 
no. Por un lado, la postura de la justicia chilena que prohíbe la exhibición de la película "La última tentación de Cristo" debido a que vulnera el derecho al honor de Cristo y sus creyentes y, por el otro, la posición de la CIDH que vuelca la decisión de los tribunales del país sudamericano, exigiendo las modificaciones necesarias para que el filme pueda ser exhibido, argumentando el derecho a la libertad de expresión y de pensamiento. Ante ello ¿Por qué la justicia chilena dio prioridad al honor por encima de otros derechos? ¿Qué razonamiento operó en esa sentencia? ¿Por qué la CIDH no estuvo de acuerdo con lo señalado por los tribunales de Chile? ¿Qué argumentó? ¿Por qué el cambio fue tan abrupto de una decisión a otra? ¿Cuáles fueron las diferencias?

Para responder a estas preguntas se exploran los argumentos teóricos del constitucionalismo y del republicanismo. Se observará que los argumentos de la $\mathrm{CIDH}$ estuvieron anclados dentro de la tradición liberal política, mientras que los del Tribunal de Apelaciones de Santiago a los principios republicanos muy cercanos al comunitarismo; ${ }^{3}$ de ahí que se puedan entender las diferencias en cada una de las sentencias. A continuación se hace una comparación de ambos dictámenes de las Cortes tomando como base los fundamentos teóricos señalados para luego constatar si la hipótesis planteada tiene sustento.

\section{LIBERALISMO Y REPUBLICANISMO EN LAS INTERPRETACIONES DE LAS INSTANCIAS JUDICIALES}

El planteamiento constitucional y el republicano provienen de tradiciones teóricas distintas. El constitucionalismo afianza sus raíces en el liberalismo político, mientras que el republicanismo dentro de la tradición comunitaria ${ }^{4}$. A continuación se exponen esas distinciones a la luz de las sentencias señaladas.

\subsection{Derechos y autonomía personal vs. virtuosismo cívico y autogobierno}

Al liberalismo se le identifica de manera especial con las declaraciones de derechos. Se afirma que uno de los momentos cruciales en la defensa de éstos lo constituyó la lucha emprendida por los liberales con el objetivo de separar la iglesia del Estado. Gargarella, R. (2002, p. 76) señala que el fundamento de esta idea consistió en impedir que algún grupo o mayoría impusiera sus creencias sobre aquellos que mantenían convicciones diferentes al resto de las personas de esa sociedad, estableciéndose un 'muro' que separó lo público de lo privado y preservándose la autonomía personal. Este principio tornaba visible el individualismo defendido por esta tradición teórica que enfatizó la importancia de que cada persona fuera respetada y tratada adecuadamente sin importar sus convicciones más íntimas.

Lo anterior se encuentra presente en la sentencia de la CIDH sobre el caso de la película "La última tentación de Cristo", ya que en ella se hace referencia explícita al artículo 13 de la Convención Americana de Derecho Humanos, el cual señala que toda persona tiene derecho a la libertad de pensamiento y expresión y [...] que éstos no pueden estar sujetos a previa censura (2001, p. 26-27). Esta afirmación pone de manifiesto la defensa de la libertad del individuo y la autonomía de la que cada uno es dueño, siendo posible la manifestación libre de las ideas sobre cualquier intento de censura previa, oponiéndose claramente a la prohibición que hizo el Estado chileno del filme en cuestión.

Siguiendo a Rawls, J. (2012), se puede entender que para el liberalismo, la libertad es un principio no negociable, pues "cada individuo tiene un derecho igual al esquema de libertades básicas que sea compatible con un esquema semejante de libertades para los demás" (Rawls, J. 2012, p. 67-68) ${ }^{5}$. Según este autor, las libertades básicas son la libertad política [...] y la libertad de expresión y de reunión; la libertad de conciencia y de pensamiento; la libertad de la persona [...] y la libertad respecto al arresto y detención arbitrarios.

La afirmación anterior justifica lo expresado por la Corte Interamericana en la sentencia del filme, ya que puso por encima de cualquier principio a la libertad. Asimismo, el órgano internacional no fue omiso a los perjuicios que la libertad trae consigo y, ante ello resaltó que frente

3 - Se está al tanto de que existen muchas versiones del republicanismo y del comunitarismo que podrían mostrar que son visiones opuestas, se concuerda con Gargarella, R. (1999b, p. 177) que si se toma un mínimo común denominador del comunitarismo y del republicanismo siempre se tenderá a encontrar un "margen de coincidencias sustantivas entre ambas posturas".

4 - Se sabe que subsisten diversos tipos de republicanismo; sin embargo, para los fines analíticos de este documento se siguió lo planteado por Gargarella, R. (2002), quien se refiere principalmente a la tradición republicana anglosajona que incluye a aquellos que en Estados Unidos fueron ubicados como los 'antifederalistas'. Se decidió hacer este recorte debido a que permite contrastar de manera más efectiva los argumentos de ambas instancias de justicia.

5 - Las cursivas en el cuerpo del texto son mías. Cabe señalar que Rawls, J. (2012) se inscribe dentro de una postura igualitaria del liberalismo. 
situaciones como la de la película, subsisten mecanismos ulteriores de queja que sirven de garantía en caso de que alguien se sienta agraviado por el ejercicio de la libertad de otro. El mecanismo se utiliza para que "personas, grupos, ideas o medios de expresión no queden excluidos del debate público" (CIDH, 2012, p. 24). Así, "cualquier persona afectada por informaciones inexactas o agraviantes, emitidas en su perjuicio tiene el derecho de efectuar por el mismo órgano de difusión su rectificación o respuesta" (2012, p. 25). Y es que a pesar de la existencia de estos criterios, los tribunales chilenos procedieron a prohibir determinantemente la exhibición de "la última tentación de Cristo" bajo el argumento de la violación al honor, dejando ver que en su decisión no primó el principio no negociable señalado por Rawls, J. (2012): la libertad ${ }^{6}$.

Por lo anterior, una de las principales objeciones que señaló la CIDH a la resolución judicial de Chile fue que privilegió el derecho al honor en perjuicio de la libertad de expresión, contraviniendo el principal fundamento liberal. $Y$ es que, el motivo de rechazo a la exhibición de la película en la Corte chilena se fundamentó, entre otras cosas, en que resultaba "ofensiva a la figura de Jesucristo, y por lo tanto, afectaba a quienes peticionaron ante la justicia, a los creyentes y demás personas que consideran a Cristo como su modelo de vida" (CIDH, 2001, p. 24-25).

Asimismo, la CIDH señaló que, si bien el derecho al honor debe de ser protegido, éste no debe de perjudicar el ejercicio de la libertad de expresión y el derecho a recibir información. De tal manera que en la tensión existente entre la libertad de expresión y el derecho a la honra, los tribunales chilenos, según la Corte Interamericana, violentaron el principio de indivisibilidad de los derechos humanos al fallar a favor de la segunda (CIDH, 2001, p. 25).
Sumado a ello, en referencia a la prohibición del filme, el órgano internacional apuntó que los individuos no sólo tienen el derecho de expresarse libremente sino también el de buscar, recibir y difundir informaciones de toda índole, por lo que, consideró que la censura de la película violentó estos ideales (CIDH, 2001, p. 27).

Así es que, desde el liberalismo, los derechos fundamentales individuales (como son las libertades mencionadas) son los límites principales al poder político y constituyen un terreno inviolable por él mismo. Como afirma Bovero, M. (2011, p. 18), "dichos derechos son aquello ante lo que el poder carece de poder, aquello de lo que no puede disponer; tanto en el sentido de que no puede adoptar decisiones que lesionen o nieguen dichos derechos, como en el sentido de que debe de asegurar su disfrute por parte de los titulares, que son todos los individuos"'.

En ese sentido, Sandel, M. (1997) -uno de los más fuertes exponentes del republicanismo contemporáneo- señala que de acuerdo con el liberalismo, ser libre es tener el derecho de perseguir los propios valores, intereses y fines, la propia visión de la buena vida, sea la que sea, pero respetándose siempre el derecho de los demás a hacer lo mismo. Ante ello, el Estado no debe tratar de formar en sus ciudadanos finalidades o virtudes particulares, al contrario, debe de ser neutral entre concepciones rivales ya sea morales o religiosas ${ }^{8}$.

El razonamiento anterior se hace explícito en la sentencia de la CIDH sobre la película en cuestión, pues señala que la libertad de expresión es la piedra angular de toda sociedad democrática y que ésta es válida aún para informaciones que chocan, inquietan u ofenden al Estado 0 a una fracción cualquiera de la población. Por lo que -señala la Corte-, al subsistir en Chile un sistema de censura previa a la exhibición y producción cinematográfica se atenta contra el derecho a la libertad de pensamiento y de expresión de los ciudadanos (2001, p. 28).

6 - Como se aprecia hasta aquí, la libertad defendida por el liberalismo es negativa, lo cual significa que resalta la facultad de realizar o no ciertas acciones sin ser impedido por los demás, por la sociedad como un todo orgánico o, más sencillamente, por el poder estatal. Se trata de gozar de una esfera de acción más o menos amplia, no controlada por los órganos de gobierno del Estado (Berlin, I. 1974).

7 - Una de las maneras que se formuló para realizar el ideal de limitar al poder fue la creación de un sistema de pesos y contrapesos o de división de poderes que otorgó un poder de veto a las autoridades estatales (ejecutivo, diputados, senadores e instancias judiciales) con el fin de que entre ellas subsistiera una especie de control endógeno o, en otros términos, de accountability horizontal. Dicha separación de poderes se instauró para prevenir el abuso de poder del Estado, ante su posible interferencia en la vida privada de las personas. Así, cuando se habla de constitución, explica Bovero, M. (2011, p. 16-17), se entiende el documento normativo que instituye la estructura de una colectividad política (de un Estado) en conformidad con dos requisitos esenciales: a) una declaración de los derechos fundamentales; b) una organización de los órganos de decisión colectiva inspirada en (una cierta interpretación de) el principio de la división y/o separación de poderes. Ahora bien, la vinculación con la democracia y, por lo cual se puede hablar de constitucionalismo democrático, ocurre cuando además de los dos requisitos señalados se añaden las seis reglas mínimas señaladas por Bobbio, N. (2005, p. 381) y reiteradas por Salazar, P. (2011).

8 - El liberalismo reclama que el Estado no interfiera en la moral privada de los individuos, pues le interesa blindar la vida personal de cada uno frente a las preferencias circunstanciales que pueda tener el gobierno de turno (Gargarella, R. 1999b). 
Por lo anterior, se aprecia que la prioridad de la CIDH fue el respeto de los derechos fundamentales y del individuo como persona valiosa en sí misma y no sacrificable por el bien de la colectividad, dando lugar a la autonomía personal por encima de cualquier interferencia estatal 0 de otro individuo.

Así, lo que se encuentra detrás de la decisión que sanciona al Estado chileno por violar la libertad de pensamiento y de expresión de la Convención Americana, es la concepción filosófica contractual e iusnaturalista que enfatiza una mirada racional e individualista y que considera al Estado como una creación artificial, antítesis del hombre natural (Bobbio, N. y Bovero, M. 1994). Es por ello que a diferencia del republicanismo -como se verá más adelante-, en la relación individuo-sociedad, el liberalismo le otorga primacía al individuo, siendo éste el punto de partida para la creación del Estado. "El Estado está creado para el individuo y no el individuo para el Estado" (Bovero, 2011, p. 22). Ejemplo de lo anterior es el fallo de la Corte Interamericana de Derechos Humanos sobre este caso.

Ahora bien, el planteamiento republicano dista mucho de lo apuntado hasta aquí. Esta perspectiva tiene una preocupación especial por el ideal del autogobierno colectivo, el cual puede ser identificado con la defensa de la libertad positiva ${ }^{9}$, en contraste con la libertad negativa propuesta por el liberalismo.

Como Skinner sostiene, "una república que se autogobierna sólo puede perdurar si sus ciudadanos cultivan la virtud: capacidad que permite por voluntad propia servir al bien común, y de este modo defender la libertad de la comunidad, para, en consecuencia, asegurar el camino hacia la grandeza, así como la propia libertad individual" (Skinner, citado en Ovejero et al., 2004, p. 25).

En el mismo sentido, Sandel, M. (1997, p. 3) señala que en una república es necesario el conocimiento de los asuntos públicos y una capacidad de deliberar sobre el bien común, lo cual, requiere una disposición moral, es decir, un sentido de pertenencia a la comunidad ${ }^{10}$.
Las afirmaciones anteriores hacen eco en la resolución del Tribunal de Apelaciones de Santiago (TAS), donde se señala que la película "La última tentación de Cristo" atentó contra el bien de la comunidad, ya que "presentó a la figura de Jesucristo -que tan decisiva influencia ha ejercido en la historia y cultura de la humanidad- de tal modo deformada y humillada, que su honra aparece vulnerada gravemente" (TAS, 1997, p. 4). Para reforzar lo anterior argumentó que esta situación violenta a la comunidad chilena dado que "la figura de Cristo, como es de público y notorio conocimiento, es venerada por la mayor parte de la población del país" y, ante ello, "debe considerarse prioritariamente a la doctrina cristiana entre aquellos valores esenciales de la tradición chilena" (TAS, 1997, p. 14 y 17). Se argumenta también que "Jesucristo, históricamente, vivió hace dos mil años y murió crucificado, $y$-aunque este tribunal prescinde del hecho de su resurrección, cuya aceptación es materia de fe-, debe admitir que el agravio a su honra repercute o trasciende en la honra de los propios recurrentes, ligado esencialmente a su dignidad de personas, ya que ésta implica, entre otros atributos, la capacidad de determinarse conforme a valores y creencias"(TAS, 1997, p. 4).

Tras estos argumentos es claro por qué el Tribunal consideró que la película atentaba contra los valores de la comunidad en general, mereciendo su prohibición en las salas de cine. La justicia chilena engrandeció un credo religioso y lo colocó por encima de las creencias individuales, aún cuando estos valores no fueran compartidos unánimemente por todos ${ }^{11}$. Adiferencia del liberalismo que plantea una línea divisoria entre Estado e iglesia, en la resolución señalada, la argumentación es tal que pareciera que muestra a los valores cristiano-católicos como centrales en la conformación del estado chileno, a pesar de que la Constitución de Chile de 1925 separó la iglesia del Estado. Y es que la sentencia del TAS fue categórica al afirmar que como la mayoría de los chilenos veneran a Cristo o lo ven como un modelo de vida, el contenido de la película atentó las creencias más profundas de la comunidad, contraviniendo al bien común y por lo tanto a la república. De esta manera, se cristaliza la idea republicana de que los derechos encuentran su límite en las políticas del bien común (Gargarella, R. 1999b).

9 - La libertad positiva significa el poder de no obedecer otras normas que las que me he impuesto a mí mismo, es decir, ser libre no significa no tener leyes, sino darse leyes a sí mismo (Berlín, 1974). Rousseau, J. desarrolla este planteamiento al señalar que en el contrato social se encuentra una forma de asociación que defiende y protege de toda fuerza común a la persona y a los bienes de cada asociado y mediante la cual, cada uno, uniéndose a todos los demás, obedece a sí mismo y queda tan libre como antes (Rousseau, J. 2004, p. 55). Cabe señalar, de igual manera, que algunos exponentes del republicanismo como Petit (2004) entienden a la libertad como no dominación.

10 - Se aclara que a diferencia del comunitarismo, el republicanismo no se compromete en lo general con el respeto de una concepción moral robusta, sino con ciertos valores institucionalmente circunscritos (Gargarella, R. 1999b).

11 - En 1997, año de la sentencia del Tribunal, el porcentaje de chilenos que se declaraban católicos era de 74\% (Latinobarometro.org, 1997). 
Otro rasgo fundamental de esta perspectiva teórica es que considera que "sin un ciudadano identificado con su comunidad y preocupado porla suerte de sus conciudadanos, la estabilidad del proyecto republicano se torna imposible" (Gargarella, R. 2002, p. 91). Ante ello, el republicanismo propone un conjunto de cualidades y valores que son necesarios de exaltar en el ciudadano virtuoso, mientras que los defectos o vicios de conducta son rechazados.

En relación con este asunto, el TAS resalta que aunque el filme se encuentra basado en el evangelio, muestra a Cristo ausente de muchas virtudes con las cuales comúnmente se le asocia, lo cual repercute en las mismas virtudes de sus seguidores. La justicia chilena señala que

El Cristo que se representa en el filme es un hombre inseguro, de poca personalidad [...] un tanto histérico y, sobre todo, patético, absurdamente extrovertido para decir que es un mentiroso, un cobarde, que su Dios es el temor, y que si no mata, no roba, no es porque teme hacerlo. [...] Su pobre expresión oral y su sensiblería sólo permiten dar una imagen absurda y rebajada del ser que ha influido sustancialmente en la filosofía, en las religiones cristianas y en la historia universal y en las vidas de millones de personas" (TAS, 1997, p. 13).

De lo anterior se desprende que la película no sólo ofendió a Cristo sino también a los creyentes y a la Iglesia Católica, a los cuales, muestra como carentes de los valores fundamentales (TAS, 1997, p. 18). Asimismo, se apunta que "al estar Cristo representado como un ser indeciso, confundido, de poca personalidad, y verse escenas que por respeto a Él y a sus seguidores no pueden exhibirse sin que ello ofenda a quienes lo tienen como Dios personificado para el bien de la humanidad" (TAS, 1997, p. 18-19).

Por lo mencionado, la sentencia de la justicia chilena privilegia los valores y virtudes por sobre la libertad de expresión y, además, exalta un credo religioso, asumiendo que éste es compartido por la mayoría de los habitantes del país sudamericano, mostrando con ello el realce de la fuerza moral en una decisión pública que arroja cuestionamientos sobre la libertad que tienen los individuos de cultivar los valores que les parezcan los más convenientes.

Y es que, otro elemento importante del republicanismo, conectado con lo anterior, es la necesidad que tiene esta visión teórica de plantear una concepción de vida buena que fortalezca los intereses de la comunidad política, pues, a diferencia del liberalismo, la visión republicana sobrepone a la sociedad por encima del individuo, siendo éste un producto de ella y no a la inversa.

Para el republicanismo, entonces, resulta aceptable un Estado que se comprometa con ciertos modelos de excelencia humana (Gargarella, R. 2002, p. 92), ya que propone un proyecto formativo consistente en preocuparse por las condiciones de vida social, cultural, política y económica para formar los hábitos, las virtudes y las disposiciones de la ciudadanía (Sandel, M. 1997). En lo anterior, se encuentra implícito uno de los rasgos más característicos de la tradición republicana, el cual apunta que el Estado no puede ser neutral con respecto al carácter moral y cívico de los ciudadanos como lo exige el liberalismo. Se requiere, ante todo, de un Estado interventor y formador de virtud en sus ciudadanos; un Estado que, visto desde la visión liberal, pone en riesgo la libertad de las personas.

Este rasgo de la visión republicana queda evidenciado en la sentencia del Tribunal chileno, cuando señala que "en el filme la imagen de Cristo es deformada y minimizada al máximo. De esta manera, el problema se plantea en si es posible, en aras de la libertad de expresión, deshacer las creencias serias de una gran cantidad de hombres. La Constitución busca proteger al hombre, a sus instituciones y a sus creencias, pues estos son los elementos más centrales de la convivencia y la pertenencia de los seres humanos en un mundo pluralista". Y en seguida sentencia, "pluralismo no es enlodar y destruir las creencias de otros ya sean estos mayorías o minorías sino asumirlas como un aporte a la interacción de la sociedad en cuya base está el respeto a la esencia y al contexto de las ideas del otro" (TAS, 1997, p. 22).

Lo anterior expone la postura republicana de la Corte de Chile, al disponer del aparato del Estado para el cultivo de ciertas concepciones religiosas en detrimento de otras. Así, el Tribunal resalta que la Constitución busca proteger las creencias de los individuos, pero al mismo tiempo se contradice debido a que los valores que defiende son sólo los de la mayoría cristiana que habita ese país. Además, con el argumento del pluralismo se censura la exhibición del filme, siendo esto paradójico debido a que la misma película representa un conjunto de ideas de quienes no comparten los valores exaltados por Cristo y sus seguidores. Ante ello, la censura a la película se enfoca en el respeto de las creencias mayoritarias por encima de la libertad de pensamiento del individuo, contraviniendo los argumentos expuestos por la CIDH y mostrando el carácter no liberal de la sentencia. 


\subsection{El papel del Estado: liberalismo vs. republicanismo}

Como se ha señalado, a diferencia del republicanismo, el planteamiento liberal exige la conformación de un Estado neutral que no intervenga en la vida privada de las personas ni intente moldear o imponer una concepción de vida buena ${ }^{12}$. Desde esta visión, Kant, I. (2004) señala que el papel del Estado es establecer las condiciones jurídicas para que los individuos persigan sus propios fines sin tratar de predeterminar mediante el derecho esos objetivos. El régimen que así lo hiciera aun con benevolencia, sería un despotismo paternal adverso a sus derechos, estableciéndose así una distinción clara entre los fines de la sociedad política y los de sus miembros.

En referencia a estos argumentos, resulta ilustrativo lo dicho sobre la libertad de conciencia en la sentencia de la Corte Internacional. En sus alegatos, la Comisión Interamericana opinó que Chile violó el artículo 12 de la Convención que exige al Estado abstenerse de interferir en la adopción, mantenimiento o cambio de convicciones personales o religiosas. Según el organismo, el ente estatal no debió utilizar su poder para proteger la conciencia de los ciudadanos al censurar y prohibir la exhibición de la película. Al contrario, debió permanecer neutral, garantizando dentro de un marco de pluralidad la manifestación de las diversas expresiones de culto (CIDH, 2001, p. 29).

Por lo anterior puede apreciarse que los juicios de la Comisión están apegados claramente a la tradición del liberalismo político, pues, casos como el que se analiza aquí, conducen a esta tradición teórica a establecer una drástica división entre la esfera privada y la pública; entre lo personal y lo político, exigiendo, tanto a los funcionarios públicos como a los ciudadanos que "<<pongan entre paréntesis >> sus propias concepciones del bien en sus discusiones públicas acerca de los alcances del poder coercitivo estatal"(Gargarella, R. 1999, p. 129).

Y es que la defensa de los derechos individuales y los límites impuestos al poder, como se ha dicho, son una forma de impedir que reclamos mayoritarios puedan socavar libertades fundamentales referidas a la esfera de lo privado. Gargarella, R. (1999) señala que éstas motivaciones pueden entenderse como una forma de impedir que los reclamos comunitaristas tengan éxito. En ese sentido, desde el liberalismo se exige a la comunidad respetar el derecho inviolable de cada uno a expresar sus ideas libremente, por más que aquellas contribuyan a socavar valores que el resto de la comunidad considera prioritarios. Asimismo, la tradición liberal defiende que cada individuo tiene el derecho de escoger su propio proyecto vital, aun cuando dicha elección implique adoptar una concepción del bien que todos los demás consideren equivocada.

Así, volviendo al caso del filme, de lo argumentado por la Comisión se puede considerar que la actuación de los órganos del poder judicial de Chile fue cercana al paternalismo, ya que, "prohibieron la película basándose en que la visión de los personajes presentada en la obra artística no se adecua(ba) a los estándares que en su opinión -de la justicia chilena-, deberían haberse tenido en cuenta para describirlos" (CIDH, 2001, p. 30). Es decir, no se permitió a los chilenos hacerse un juicio propio acerca de si la película exponía de manera correcta 0 incorrecta a Cristo y, al contrario, de antemano se sancionó e impidió que pudiesen mirarla, asumiendo la ausencia de crítica a la doctrina religiosa cristiana.

Lo anterior, en palabras de la Comisión, violó la libertad de conciencia y de religión de los agraviados y de la sociedad chilena en general, pues "afectó a quienes pertenecen a otros credos o no tienen convicciones religiosas, ya que se privilegió un credo en perjuicio del libre acceso a la información del resto de las personas que tienen derecho a acceder y formarse opinión sobre la obra"(CIDH, 2001, p. 30).

Como señala Rawls, J. (2012, p. 124), "la libertad puede ser restringida sólo en aras de la libertad". Es decir, el Estado debe priorizar este derecho, siempre y cuando no interfiera con la libertad de otro, por lo que, ante cualquier otro valor, la libertad siempre tiene una cualidad prioritaria. Esto último, en opinión de la Comisión, no se cumplió en la sentencia de la Corte chilena debido a que se ponderaron las convicciones religiosas por encima de los derechos a la libertad de información y de conciencia. Sin embargo, a pesar de los razonamientos vertidos por la instancia señalada, la Corte Interamericana argumentó que no existieron pruebas necesarias para sostener que se violó

12 - Se destaca, como señala Aguilar, A. (2000, p. 66-67) que "no todos los liberales creen en la neutralidad del Estado. Ni siquiera los anglosajones. [...] Los desarrollos más recientes en la teoría liberal que hacen énfasis en la justicia consideran una anomalía la inexistencia de igualdad de oportunidades entre los individuos. Rawls ha propuesto criterios de intervención estatal para lograr esta equidad". Y es que la principal crítica a la neutralidad del Estado es que "ésta consagra y acrecienta las desigualdades existentes. Así, a mayor competencia, mayor desigualdad, a mayor desigualdad, mayor desintegración de la sociedad. De allí el peligro de que la multiplicidad conduzca a la pérdida de conciencia del valor de la colectividad, a la fragmentación de la sociedad y a la reducción de la vida éticamente valiosa para la esfera pública" (Villoro citado en Aguilar, A. 2000, p. 66). 
el artículo 12 de la Convención aun cuando se presentaron varios testimonios que argumentaron sobre la violación a este derecho. El razonamiento de la CIDH señaló que con la prohibición de la exhibición de la película, no se privó a ninguna persona de su derecho de conservar, cambiar, profesar o divulgar, con absoluta libertad su religión o creencia; violándose solamente, como se señaló arriba, la libertad de expresión y pensamiento al censurar el filme.

Ahora bien, mientras que desde la visión liberal se ponen ciertos límites al Estado para que no interfiera en la libertad de los asociados, en la perspectiva republicana la ley asegura la libertad obligando a cada uno a actuar de manera determinada (Ovejero et al., 2004, p. 34). Así, el Estado no sólo otorga al individuo derechos vinculados a la libertad, sino que además le exige asumir deberes que van más allá del respeto por los derechos de los demás (Ovejero et al., 2004, p. 24), es decir, conduce a los ciudadanos a contraer un compromiso con los intereses de la sociedad en su conjunto.

Bajo este esquema, es necesario que los individuos sean políticamente activos y comprometidos con el resto de los miembros del cuerpo social, exigiéndoseles que ante cualquier amenaza externa que ponga en riesgo a la comunidad, deban defenderla y vigilar su salvaguarda. En ese sentido, es que el Estado tiene un papel fundamental en el cultivo de las virtudes adecuadas en sus ciudadanos para su propia supervivencia. Y es que, el republicanismo comparte el planteamiento comunitario que postula "un Estado activista, comprometido con ciertos planes de vida y con una organización de la vida pública" (Gargarella, R. 1999, p. 128) $)^{13}$.

Estos argumentos se materializan en la sentencia de la Corte chilena cuando señala que la Constitución política debe preservar los valores esenciales de la tradición chilena, siendo parte prioritaria la doctrina cristiana, dado que la mayoría de la población comparte esos valores religiosos (TAS, 1997, p. 17). Asimismo, cuando continúa diciendo que "cuidar la necesidad de información o de expresión tiene una estrechísima relación con la veracidad de los hechos y por eso deja de ser información o expresión la deformación histórica de un hecho o persona. Por esto es que los juzgadores creen que el derecho de emitir opinión es el derecho a calificar una realidad pero nunca el deformarla haciéndola pasarporotra"(TAS, 1997, p. 22).
Lo anterior muestra la toma de postura de la Corte chilena en favor de un credo religioso y el rechazo hacia discursos que promueven una crítica hacia lo que la mayoría cree y defiende. $Y$ es que cuando los republicanos sugieren la adopción de políticas de protección de la comunidad, lo que muestran es su pleno rechazo al ideal característicamente liberal referido a la neutralidad e imparcialidad del Estado. Lo que los liberales le exigen es que no utilice su poder coercitivo en nombre de alguna religión o filosofía de vida, de modo tal que prohíba algún culto.

De hecho, Gargarella, R. (2002, p. 95) señala que muchos antifederalistas republicanos -opositores al modelo liberal de pesos y contrapesos que proponía evitar el mayoriteo en las diversas instancias del Estado- promovían que el Estado asumiera como propia alguna religión particular, bajo la idea de que la religión debía de actuar como guardiana de la moral. Asimismo, otros antifederalistas no encontraron contradicción alguna entre la defensa de la libertad individual y el establecimiento de leyes muy estrictas contra los 'libelos difamantes', en tanto ello, sirviera para salvaguardar un cierto 'clima moral' en la comunidad.

En el caso en análisis, se percibe cómo la Corte chilena asumió como visión moral del país a la religión cristiana, estableciendo que la difamación de Cristo hecha por la película en cuestión representó una falta a la nación, violando el artículo 19 consistente en el respeto y protección a la honra. El argumento de la justicia del país sudamericano señaló que "la grandeza de una nación se puede medir por el cuidado que ella otorga a los valores que le permitieron ser y crecer. Si estos se descuidan o se dejan manosear como se manosea y deforma la imagen de Cristo, la nación peligra, pues los valores en que se sustenta se ignoran". Asimismo, afirma que "cuando la deformación tiene relación con sacar de contexto el credo de otros en su dimensión histórica, en su dimensión de cuerpo, de creencias, es insultar lo más delicado del ser humano que es su necesidad y capacidad de trascendencia". Finalmente, sentencia categóricamente que "la película ofende, debilita y denigra no sólo a Cristo [...] sino que además ofende, debilita y denigra a quienes basan su fe en un Cristo Redentor y Dios y a partir de esa convicción y realidad asumen y dirigen sus propias vidas y pretenden que sus hijos también lo hagan" (TAS, 1997, p. 22).

13 - Uno de los autores que se ha reconocido cercano a esta tradición es Rousseau, quien ve la materialización de la libertad en el Estado, encontrándose supeditada a la decisión de la voluntad general, pues, aunque la libertad individual niegue dicha voluntad, el ciudadano se verá obligado a acatarla ya que sólo así podrá ser libre. Rousseau señalará que "quien se niegue a obedecer a la voluntad general, será obligado por todo el cuerpo: lo que significa que se le obligará a ser libre" (Rousseau, J. 2004, p. 61). Así, la coacción no existe realmente porque cuando una persona quiere algo diferente de lo que el orden social le da, ésta "no quiere sino su capricho y no sabe en realidad cuál es su propio bien ni cuáles son sus propios deseos" (Sabine, G. 2004, p. 450). 
Se observa con esta afirmación cómo la perspectiva republicana del Tribunal privilegió la actuación del Estado a favor de ciertos principios, quedando los derechos subordinados a las necesidades de la comunidad. Como señala Taylor, la tradición de la cual se enriquece el republicanismo "no puede insistir en la necesidad de proteger ciertos derechos frente a la propia sociedad o a expensas de ella" (Taylor, 1999, p. 131).

Y es que a diferencia del liberalismo, el republicanismo pondera los intereses del todo-social sobre el individuo, dejando de lado la neutralidad estatal. Lo anterior muestra la pretensión republicana de conformar un Estado perfeccionista que en ocasiones puede ser una alternativa bastante riesgosa (Sandel, M. 2002), pues, como se ha señalado, abre la posibilidad para que visiones mayoritarias puedan imponerse y socavar libertades y derechos individuales de las personas.

\section{CONCLUSIONES}

El análisis anterior permite constatar que la razón por la cual las sentencias de la CIDH y la de la justicia chilena fueron diferentes, radicó en que cada una estuvo anclada en principios teóricos diferentes y contrapuestos. Por un lado, la perspectiva liberal con su propuesta de respeto a los derechos, autonomía personal y Estado neutral, garante de las concepciones de vida buena de todos los individuos y sin pretensiones de orientar moral, cívica o religiosamente. Por otro lado, la visión republicana enfocada en salvaguardar el interés común, cultivando las virtudes ciudadanas y del gobierno, a través de un Estado activo, formador moral de ciudadanos, sin importar si vulnera las concepciones de vida buena de los individuos siempre que se fortalezca al colectivo.

Lo anterior estuvo materializado en las dos sentencias analizadas, mostrando claramente las diferencias: Ios tribunales de justicia de Chile acentuaron el derecho al honor en su dictamen -valor fundamental del pensamiento republicano-, mientras que la CIDH priorizó la libertad por encima de cualquier otro derecho, mostrando el talante liberal en su sentencia. Asimismo, en el caso de los tribunales del país sudamericano, el papel del Estado como ente interventor se hizo patente al proteger un credo religioso dado que éste fue identificado como uno de los ejes morales de la mayoría de la población chilena, haciendo evidente el rol perfeccionista y protector de la autoridad estatal. De manera contraria, las críticas de la Comisión a este respecto estuvieron dirigidas fundamentalmente a la falta de neutralidad en la decisión de las autoridades de Chile.
En suma, la materialización de ambas posturas no sólo permite ver cómo operan ambas concepciones en las interpretaciones de los problemas sociales, sino también permite mirar algunas de las consecuencias negativas como poner en peligro la libertad y los derechos de expresión y pensamiento de las personas al supeditar las decisiones al interés de la mayoría. Asimismo, al establecer un estado perfeccionista y romper con la neutralidad liberal, se puede convertir a la fuerza estatal en un riesgo, al tratar de moldear modelos de conducta adecuándolos a principios religiosos.

No obstante lo anterior, no quiere decir que el liberalismo no tenga consecuencias negativas; algunas de ellas referidas fundamentalmente a su vertiente económica (que no se aborda aquí) y al exacerbado individualismo que promueve en ocasiones. La sentencia de la $\mathrm{CIDH}$ dejó en claro que a pesar de los defectos del liberalismo, la defensa de los derechos y la libertad de las personas debe de ser un principio irrenunciable en toda decisión que tomen las autoridades estatales, esto con el objetivo de que no se repitan situaciones como la analizada aquí sobre el caso de "Laúltimatentación de Cristo".

\section{REFERENCIAS BIBLIOGRÁFICAS}

I. Aguilar, Antonio (2000), "El sonido y la furia: crítica de la persuasión multicultural" en Isonomía, XII, pp. 53-73.

II. Berlin, Isaiah (1974), "Dos conceptos de libertad" en Isaiah Berlin, Libertad y necesidad en la historia, Revista de occidente, Madrid, pp. 132-184.

III. Bobbio, Norberto (2005), Teoría general de la política, Trotta, Madrid.

IV. Bobbio, Norberto y Bovero, Michelangelo (1994), Sociedad y estado en la filosofía moderna. Modelo iusnaturalista y el modelo hegeliano-marxiano, FCE, México.

V. Bovero, Michelangelo (2011), "Prefacio. Nuevas reflexiones sobre democracia y constitución" en Pedro Salazar, La democracia constitucional Una radiografía teórica, México, FCE.

VI. Corte Interamericana de Derechos Humanos (CIDH) (2001), Caso "La última tentación de Cristo" (Olmedo Bustos y otros) vs. Chile, Sentencia 5 de febrero de 2001.

VII. Gargarella, Roberto (1999), "El embate comunitarista" en Roberto Gargarella, Las teorías de la justicia después de Rawls. Un breve manual de filosofía política, Paidós, Barcelona.

VIII. Gargarella, Roberto (1999b), "El republicanismo" en Roberto Gargarella, Las teorías de la justicia 
después de Rawls. Un breve manual de filosofía política, Paidós, Barcelona.

IX. Gargarella, Roberto (2002), "La comunidad igualitaria y sus enemigos. Liberalismo, republicanismo e igualitarismo", en Andrés Hernández (Comp.), Republicanismo contemporáneo. Igualdad, democracia deliberativa y ciudadanía, Siglo del hombre editores, Universidad de los Andes, Bogotá.

X. Kant, Immanuel (2004), Principios Metafísicos de Derecho, España, Espuela de plata.

XI. Ovejero, Felix, et. al., (2004), "Introducción", en Ovejero et. al. (Comps), Nuevas ideas republicanas. Autogobierno y libertad, Paidós, Barcelona.

XII. Pettit, Philip (2004), "Liberalismo y republicanismo", en Ovejero et. al. (Comps), Nuevas ideas republicanas. Autogobierno y libertad, Paidós, Barcelona.

XIII. Rawls, John (2012), Teoría de la justicia, FCE, México.

XIV. Rousseau, Jean-Jacques (2004), El contrato social, España, Istmo.

XV. Sandel, Michael (1997), "The constitution of the procedural republic: liberal rights and civic virtues", en Fordham law review, Volumen 66.

XVI. Sabine, George (2004), "El redescubrimiento de la comunidad: Rousseau" en George Sabine, Historia de la teoría política, México, FCE.

XVII. Salazar, Pedro (2011), La democracia constitucional. Una radiografía teórica, FCE, México.

XVIII. Tribunal de Apelaciones de Santiago (1997), García Valdés, Sergio y otros con Consejo de Calificación Cinematográfica. [Recurso de protección. - 17-6-1997], documento electrónico.

[http://www.docstoc.com/docs/122941623/TOMO-XCIV---A\%EF\%BF\%BDo-1997]. 